\title{
A Perspective: Has Masking, Hand Washing, Distancing and Sheltering in Place for the COVID-19 Pandemic Adequately Addressed Immunity?
}

\author{
Nancy N Byl* \\ Department of Physical Therapy and Rehabilitation Science, School of Medicine, University of California, USA
}

*Corresponding author: Nancy N Byl, Professor Emeritus, Department of Physical Therapy and Rehabilitation Science, School of Medicine, University of California, San Francisco, USA.

Received Date: December 19, 2020

Published Date: January 29, 2021

\section{Opinion}

Around the world, 2020 will be remembered as the year challenged by the coronavirus. Some people continue to ask: "Is the coronavirus really that serious?" If casinos, theaters and churches are closed, heaven and hell have apparently agreed on the same thing: the coronavirus is serious! Despite the early warnings in China in December of 2019, the United States was not successful in reducing the incidence, prevalence or fatalities due to COVID 19. Guidelines to wear masks, maintain 6-foot distancing, hand washing to sheltering in place did not stop the spread of the coronavirus, minimize the fatality rate nor decrease the demand on our Intensive Care Units [1-4]. Further the guidelines have not directly addressed immunity nor provided insight to distinguish those who would suffer severe disease, sustain fatal effects or survive with minimal or severe impairments [5-7].

As a health care professional for 58 years (now 80 years of age and still volunteering to see patients), this current pandemic is not my first exposure to a major epidemic. Epidemic refers to a disease that spreads over a wide area with many individuals taken ill at the same time. A pandemic is a type of epidemic that affects a wider geographical area with a significant portion of the population becoming affected [8]. As a youth, I experienced the polio epidemic (appeared in 1916 and continued as a threat for 40 years) [9-11]. During those years, we stopped swimming, having sleep overs, birthday parties, gathering in parks, playgrounds and movie theaters. But we did continue to attend school, participate in sports, attend church services and participate in school performances.
We also survived a World War and a major depression. With the coronavirus, more individuals have been infected and more people have died compared to the polio epidemic. However, will we also suffer a major economic recession after COVID-19?

This current coronavirus scare has overshadowed our existing pandemics including obesity, diabetes, high blood pressure, cardiopulmonary disease and addiction. Just in the US alone, over $40 \%$ of adults and $19 \%$ of children are obese [12]. Recently I saw a statement: "Wearing a mask inside your home is not necessary to prevent the corona virus but rather to prevent obesity". In the US alone, 34.2 million people of all ages have diabetes $10.5 \%$ of the population; $13.0 \%$ of all US adults) [13]. Since 1999, more than 760,000 people have died from a drug overdose, with the death rate ramping up to over 40,000/year [14]. Even the seasonal flu continues to be a major threat despite an aggressive vaccination program. For those over 65 years, $70-80 \%$ of deaths are due to the flu. The CDC estimates influenza results in 9-45 million illnesses / year and 140,000-810,000 hospitalizations [15,16]. In all of these epidemics/pandemics, we seem to be missing the strategies to improve positive health, healing and immunity.

Research supports physical activities as an essential factor for healthy aging, positive fitness and good immunity $[17,18]$. Masking up and engaging in activities outdoors with respectful distancing, allows everyone to walk, bike, ski, play tennis, soccer, football, volleyball or baseball. Individuals can also do aerobic, flexibility, balance, coordination, endurance and strengthening exercises at 
home, in the gym or in the community. Where possible, integrating dual tasking and learning during physical exercise can further strengthen the immune system and facilitate the upregulation of dopamine and endorphins to promote a sense of well-being. Replacing sitting with squatting can enable older individuals and those with impairments to be prepared to get up off the floor if they fall.

To maximize immunity and the potential for healing, one needs to maintain good oxygen delivery [19-22]. This requires adequate hydration, diaphragmatic breathing and strengthening inspiration and expiration. Improved breathing enhances pulmonary health, posture, coordination and endurance [23-26]. Muscle strengthening exercises can further counter fatigue, enhance energy and facilitate immunity. Innovative techniques like blood flow restriction ((BFRputting a strap on the extremity during strengthening) [27-28] or remote ischemic limb conditioning (RLIC- doing intermittent blood flow restriction with a blood pressure cuff) [29-31] can enhance strength and endurance as well as improve blood flow and healing. These techniques can be achieved without going to the gym or having supervised therapy.

Good nutrition and a healthy gut are critical to strong immunity [32-37]. A balanced diet including fruits, vegetables, and proteins is recommended. Ideally one should include essential nutrients to strengthen immunity through a healthy daily diet, but some individuals may require adding pro biotics, vitamins (e.g. B6, C, D, and K2) along with supplements of Turmeric and calcium [37]. If individuals cannot afford healthy nutrition, it is critical to reach out to community organizations to help. For those on a variety of prescription drugs, the primary physicians should be contacted to assure the supplements are from a quality company and do not interfere with prescribed medications.

Living in a safe environment, getting a good night of sleep and maintaining a healthy brain are critical to positive health and immunity. Laughing, engaging in rich historical or political discussions with household partners/friends and engaging in learning activities are critical to brain health. Adding enriched activities like brain training exercises [38,39]. Lateral thinking puzzles, cross word puzzles, scrabble, dominoes, assembling puzzles/model and playing problem solving challenging games [40] can facilitate alertness and potentially ward off dementia secondary to aging, isolation and stress. Integrating stress management and relaxation strategies also can help maintain a healthy brain and improve sleep and alertness.

Zoom, google and facetime meetings try to create belongingness, communication and social engagement with relatives and friends. Virtual meetings try to create meaningful environments for decision-making, interpersonal communication, problem solving and learning. However, these engagements fall short of replacing hugging, laughing, debating, playing sports, dining out or sharing a cup of coffee with friends and family. Loneliness, insecurity, stress, decreased self- esteem, reduced self-worth, unemployment as well as depression have negative effects on immunity.

In summary, vaccination programs for the coronavirus have been instituted. However, a vaccination program alone is insufficient to control the current or future pandemics. We must develop guidelines to maximize immunity by managing the effects of climate change on our environment while promoting physical activities, healthy eating, good oxygen delivery, stress management and brain enrichment of individuals across the US and the world. We must sharpen our public health game to facilitate positive health, strong immunity, physical independence and quality of life across age as well as socioeconomic, cultural and gender diversity.

\section{Acknowledgement}

None.

\section{Conflict of Interest}

Author declares no conflict interest.

\section{References}

1. Kandemirli SG, Dogan L, Sarikaya ZT, Kara S, Akinci C, et al. (2020) Brain MRI Findings in Patients in the Intensive Care Unit with COVID-19 Infection. Radiology 297(1): E232-E235.

2. Mao L, Jin H, Wang M, Hu Y, Chen S, et al. (2020) Neurologic Manifestations of Hospitalized Patients With Coronavirus Disease 2019 in Wuhan, China. JAMA Neurol 77(6): 683-690.

3. Mahammedi A, Saba L, Vagal A, Leali M, Ross A, et al. (2020) Imaging in Neurological Disease of Hospitalized COVID-19 Patients: An Italian Multicenter Retrospective Observational Study. Radiology 297(2): E270-E273.

4. Sheehy LM (2020) Considerations for Postacute Rehabilitation for Survivors of COVID-19. JMIR Public Health ad Surveil 6(2): e19462.

5. Field-Fote E (2020) Lessons from COVID-19 on the Stepwise Development of Interventions. J Neurol Phys Ther 44(3): 177-178.

6. Bleicher A, Conrad K (2020) We Thought it Was Just a Respiratory Virus: We Were Wrong. UCSF Magazine: 13-19.

7. Oaklander M (2020) How the pandemic is changing the way we Sleep Time 17(24): 87-91.

8. Pandemic vs Epidemic. Merriam Webster.

9. Bond A (2020) We must learn from our Past. UCSF Magazine: 26-33.

10. Kurlander C (2020) The deadly polio epidemic and why it matters for coronavirus. Yahoo News.

11. Tucker JA (2020) No Lockdowns: The Terrifying Polio Pandemic of 1949-1952. American Institute for Economic Research.

12. Obesity.

13. (2020) National Diabetes Statistics Report. Estimates of Diabetes and Its burden in the United States.

14. What Is the Opioid Epidemic. Addiction Center.

15. (2021) Weekly U.S. Influenza Surveillance Report. Centers for Disease Control and Prevention.

16. A Guide to Seasonal Flu for Seniors. Aging.com.

17. Exercise Examples and Videos. Nutrition.gov. U.S. Department of Agriculture. 
18. The New and Improved Nutrition Facts Label - Key Changes. U.S. Food \& Drug Administration.

19. Albina JE, Reichner JS (2003) Oxygen and the regulation of gene expression in wounds. Wound Repair Regen 11(6): 445-451.

20. Sinno S, Lee DS, Khachemoune A (2011) Vitamins and cutaneous wound healing. J Wound Care 20(6): 287-293.

21. Yip LM (2015) Influence of oxygen on wound healing. Int Wound J12(6): 620-624.

22. Cherry GW, Hughes M (2003) Increased healing of the disrupted wound-A myth or simply enhanced angiogenesis following wounding? Personal discussions with Tom Hunt from the 1960s to the present. Wound Repair Regen 11(6): 401-404.

23. Janssens L, McConnell AK, Pijnenburg M, Claeys K, Goossens N, et al. (2015) Inspiratory muscle training affects proprioceptive use and low back pain. Med Sci Sports Exerc 47(1): 12-19.

24. Lee K, Park D, Lee GC (2019) Progressive Respiratory Muscle Training for Improving Trunk Stability in Chronic Stroke Survivors: A Pilot Randomized Controlled Trial. J Stroke Cerebrovasc Dis 28(5): 12001211.

25. Moffa A, Oliveto G, Matteo FD, Baptista P, Cardenas A, et al. (2020) Modified inspiratory muscle training (m-IMT) as promising treatment for gastro-oesophageal reflux disease (GERD). Acta Otorrinolaringol Esp 71(2): 65-69.

26. Ferraro FV, Gavin JP, Wainwright TW, McConnell AK (2020) Comparison of balance changes after inspiratory muscle or Otago exercise training. PLoS One 15(1): e0227379.

27. Ladlow P, Coppack RJ, Dharm-Datta S, Conway D, Sellon E, et al. (2018) Low-Load Resistance Training With Blood Flow Restriction Improves Clinical Outcomes in Musculoskeletal Rehabilitation: A Single-Blind Randomized Controlled Trial. Front Physiol 9: 1269.
28. Cerqueira MS, Nascimento JED, Maciel DG, Barboza Mendon JA, Vieira DB (2020) Effects of blood flow restriction without additional exercise on strength reductions and muscular atrophy following immobilization: A systematic review. J Sport Health Sci 9(2): 152-159.

29. Simpkins AN (2018) The Future of Remote Ischemic Conditioning: An Interview with Dr. David Hess. International Stroke Conference: 24-26.

30. Hess DC, Khan MB, Hoda N, Morgan JC (2015) Remote ischemic conditioning: A treatment for vascular cognitive impairment. Brain Circ 1(2): 133-139.

31. Lim SY, Hausenloy DJ (2012) Remote ischemic conditioning: from bench to bedside. Front Physiol 3:27.

32. Beth Howard (2020) Can Supplements Boost Your Immunity This Winter? Web MD.

33. (2020) Can supplements help boost your immune system? Harvard Health Publishing.

34. (2020) Vitamin and Mineral Supplement Fact Sheets. National Institutes of Health. Office of Dietary Supplements.

35. (2020) Natural Ways to Boost Your Immunity. Best Medicine.

36. Cerqueira MS, Nascimento JED, Maciel DG, Barboza Mendon JA, Vieira DB (2020) Effects of blood flow restriction without additional exercise on strength reductions and muscular atrophy following immobilization: A systematic review. J Sport Health Sci 9(2): 152-159.

37. (2020) Vitamin and Mineral Supplement Fact Sheets. National Institutes of Health. Office of Dietary Supplements.

38. brainhq from posit science.

39. Discover what your mind can do.

40. Empowering you to take control of your Brain Health. 